\title{
Sexually Violent Predator Evaluations: Empirical Evidence, Strategies for Professionals, and Research Directions
}

\author{
Holly A. Miller, ${ }^{1,3}$ Amy E. Amenta, ${ }^{2}$ and Mary Alice Conroy ${ }^{2}$
}

Several states have passed civil commitment laws that allow the precautionary detention of sex offenders who have completed their criminal sentences. Over 2,500 sex offenders have been committed across states with such statutes and several thousand more sex offenders have been evaluated. Most statutes call for an evaluation of risk by a mental health professional and, although each state statute is worded differently, three main elements common to sexually violent predator evaluations are used to guide evaluators: mental abnormality, volitional capacity, and likelihood of future sexual violence. The current article presents empirical evidence for the main tenants of these forensic evaluations, provides recommendations for evaluators in light of current limitations of evidence, and offers suggestions for future research in this area of forensic assessment.

KEY WORDS: sexually violent predator; forensic evaluation; risk assessment.

Since the mid-1990s, 16 state legislatures have passed civil commitment laws that allow the precautionary detention of sex offenders who have completed their criminal sentences (Fitch, 1998). These laws were passed in response to what is perceived as a serious social problem of sexual aggression in this country (Seto \& Lalumière, 2000). Such laws were driven by the belief that traditional civil commitment procedures were inadequate to confront the unique danger presented by sex offenders who posed a continued threat to the health and safety of members of the community. As states with such statutes pursue civil commitment for incarcerated sex offenders and as additional states pass sexually violent predator ${ }^{4}$ (SVP) statutes,

\footnotetext{
${ }^{1}$ College of Criminal Justice, Sam Houston State University, Huntsville, Texas 77341-2296.

${ }^{2}$ Department of Psychology, Sam Houston State University, Huntsville, Texas.

${ }^{3}$ To whom correspondence should be addressed at College of Criminal Justice, Sam Houston state University, Huntsville, Texas 77341-2296; e-mail: hmiller@shsu.edu.

${ }^{4}$ The terms and definitions utilized in relevant civil commitment statutes vary from state to state. Statutes use differing terms such as "sexually violent predator," "sexually dangerous individual," and "sexually dangerous person" to label offenders committed under such statutes. A table detailing the statutory terms and definitions utilized in the statutes of each of the 16 states with such laws has been provided. Although the authors acknowledge not all states use the terms, for the sake of simplicity "sexually violent predator" and "mental abnormality" will be utilized throughout this paper.
} 
mental health professional involvement within this legal arena will increase. As of June 2003, at least 2,500 SVP's were committed across the states (Marcotty, 2003). In addition, at least 17 other states have laws in place that require a determination of whether or not an offender is a SVP for the purpose of registration and/or community supervision. Most, if not all, of these offenders, as well as thousands of sexual offenders evaluated but not found to be SVP's, have been assessed by mental health professionals. Indeed, state SVP statutes explicitly provide for the involvement of mental health professionals. In Texas, to assist in the determination of whether an individual has a behavioral abnormality that makes the individual likely to engage in acts of sexual violence, the statute states that "the department required to make the determination shall use an expert to examine the person" (Texas Health \& Safety Code, 2000). Virginia's statute calls for "a mental health examination, including personal interview, of the person by a licensed psychiatrist or a licensed psychologist" (Virginia Code Annotated, 2004).

Although states may provide guidance to the mental health professional performing a sexual predator evaluation, statutes vary in the level of specificity of assistance provided. Virginia's statute, a relatively specific one, directs evaluators to "include consideration of the prisoner's score on the rapid risk assessment for sexual recidivism or a comparable, scientifically valid instrument ... and a review of (i) the prisoner's institutional history and treatment record, if any (ii) the prisoner's criminal background, and (iii) any other factor which is relevant to the determination" (Virginia Code Annotated, 2004). The California statute is specific in its recommendations of risk factors to be evaluated: "[r]isk factors to be considered shall include criminal and psychosexual history, type, degree and duration of sexual deviance, and severity of mental disorder" (California Welfare \& Institution Code, 2003). Although Texas statute explicitly calls for an assessment of psychopathy, it allows for considerable discretion on the part of the evaluator, requiring a clinical interview, "and other appropriate assessments and techniques to aid in the determination" (Texas Health \& Safety Code, 2000).

Overall, state statutory guidelines provide minimal assistance to the mental health professional who is required to evaluate the risk posed by these sexual offenders. The purpose of the current article is to present the empirical evidence for the main tenants of these forensic evaluations. Additionally, the authors will provide recommendations for evaluators in light of current limitations in the empirical evidence and offer suggestions for future research in this area of forensic assessment.

\section{BACKGROUND}

In 1997, the United States Supreme Court issued a five to four decision upholding the Kansas SVP Act (the Act) "which establishe[d] procedures for the civil commitment of persons who, due to a mental abnormality or a personality disorder are likely to engage in predatory acts of sexual violence" (Kansas v. Hendricks, 1997, p. 350). Leroy Hendricks, the first inmate to be committed under the Act, challenged his commitment before the Supreme Court on double jeopardy, ex post facto law making, and substantive due process grounds. Addressing Hendricks's first two 
claims, the Court found that the proceedings set forth in the Kansas statute were civil, not criminal in nature. Because the Act established a civil proceeding, the Court determined it unnecessary to address Hendricks's claims of double jeopardy and ex post facto law making.

The Supreme Court did address Hendricks's third claim and ruled the Act's definition of mental abnormality, "a congenital or acquired condition affecting the emotional or volitional capacity which predisposes the person to commit sexually violent offenses in a degree constituting such person a menace to the health and safety of others" (Commitment of Sexually Violent Predators Act, Kansas, 2002), satisfied substantive due process requirements. In accepting this definition, the Court ruled that three significant characteristics rendered it constitutional: (i) the mental abnormality element restricted civil commitment to a small group of dangerous individuals, (ii) the requirement differentiated between those subject to civil commitment from those subject only to the criminal justice system, and (iii) the inability to control element of the requirement legitimized the commitment of those found to be SVP's.

The criteria commonly found in state SVP commitment laws closely resemble those set forth in Kansas v. Hendricks (1997). Such laws generally include four elements: (i) a history of sexual offenses, (ii) a mental abnormality, (iii) volitional impairment, and (iv) as a result of mental abnormality, the individual is likely to engage in acts of sexual violence. The reader is referred to Table 1 for a review of statutory definitions across the 16 states with relevant civil commitment laws. Although variation exists among state definitions, the similarity of these definitions to those accepted by the Supreme Court as constitutional is clear.

Given the minimalist nature of statutory guidelines in many states, guidelines as to how to proceed with sexual predator evaluations are increasingly being developed within the mental health community (Conroy, 2002; Doren, 2002; Lanyon, 2001; Reid, 2002). Lanyon (2001) reviews the literature in six areas likely to be relevant to a sex offender civil commitment evaluation: (i) assessment of psychopathology, (ii) deviant sexual interests, (iii) recidivism risk, (iv) treatment amenability, (v) response bias, and (vi) match with formal statutory criteria. Within each area, Lanyon provides evaluators with instruments "that tend to be employed" (p. 257). Relying upon anecdotal evidence and personal experience, Reid (2002) provides mental health professionals with an overall picture of the evaluation process and advice for reviewing records, interviewing offenders, and interacting with members of the adversarial system. Conroy (2002) reviews issues related to sex offender risk assessment including actuarial and clinical assessments of dangerousness, recidivism base rates, psychopathy, available risk assessment instruments and their strengths and weaknesses, treatment, and roles the mental health professional may play within this legal context. Within each topic area Conroy examines the empirical evidence and provides useful guidelines for the mental health professional conducting a sexual predator evaluation.

More recently, Doren (2002) published a book devoted entirely to the topic of sex offender evaluations for civil commitment. He suggests the evaluator's task includes two essential components: "(1) a diagnostic formulation, usually involving the additional issue to be addressed of a specific type of predisposition, along with 


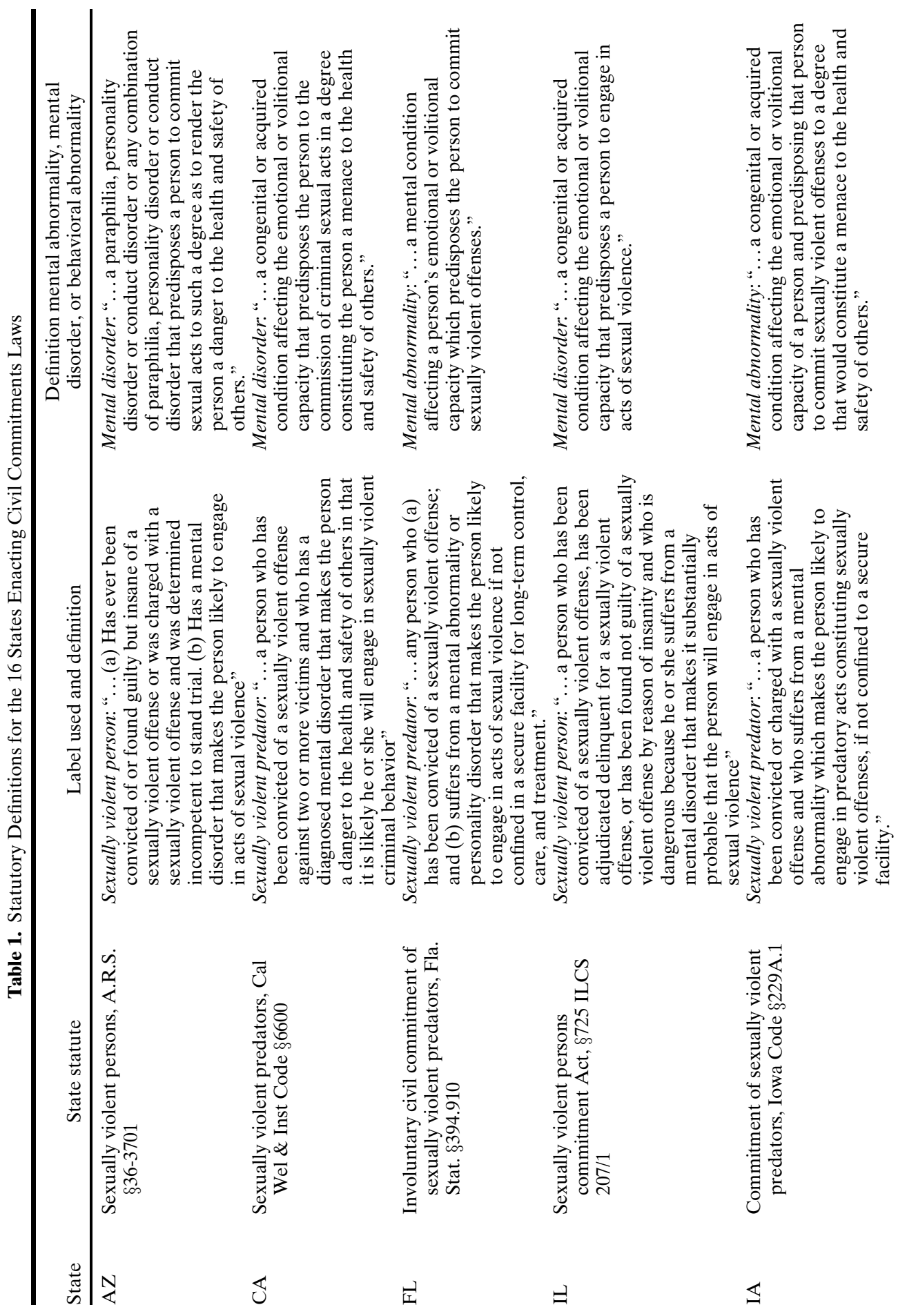




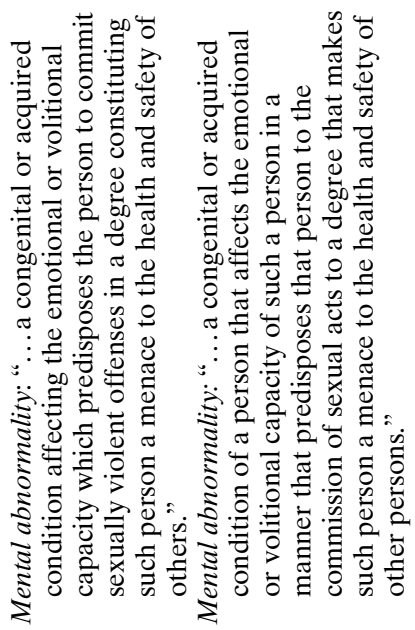

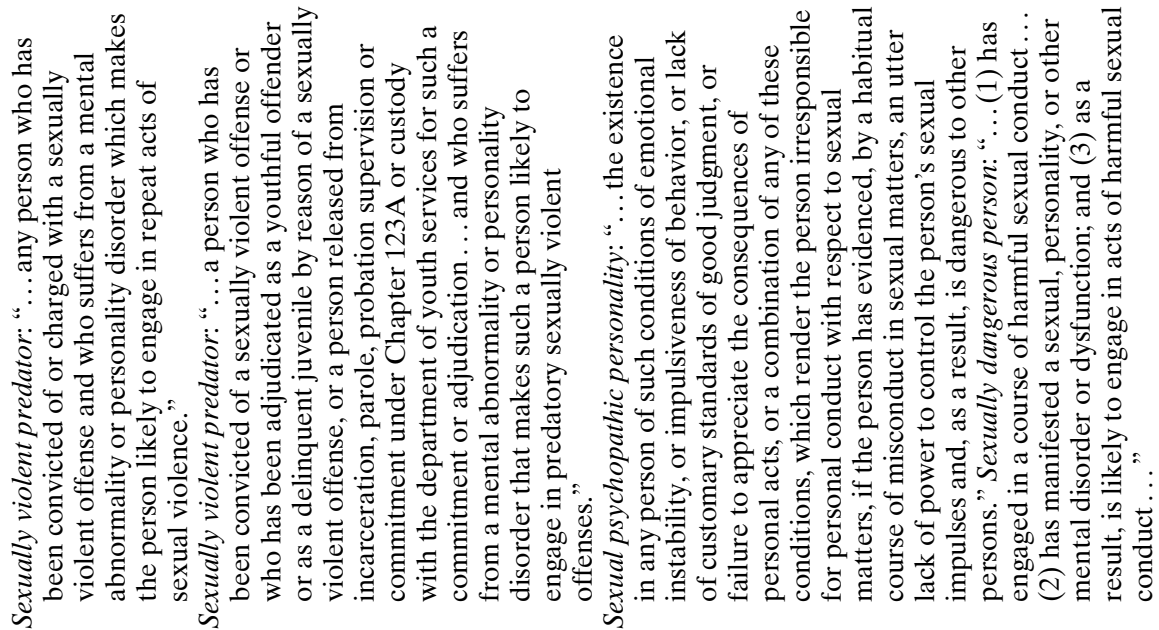

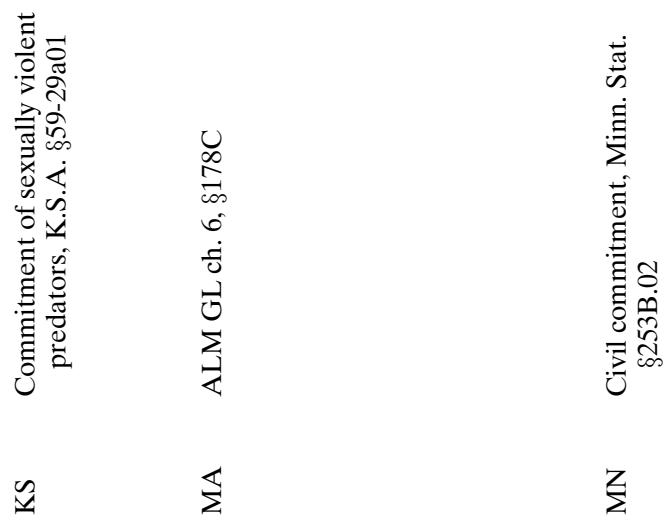




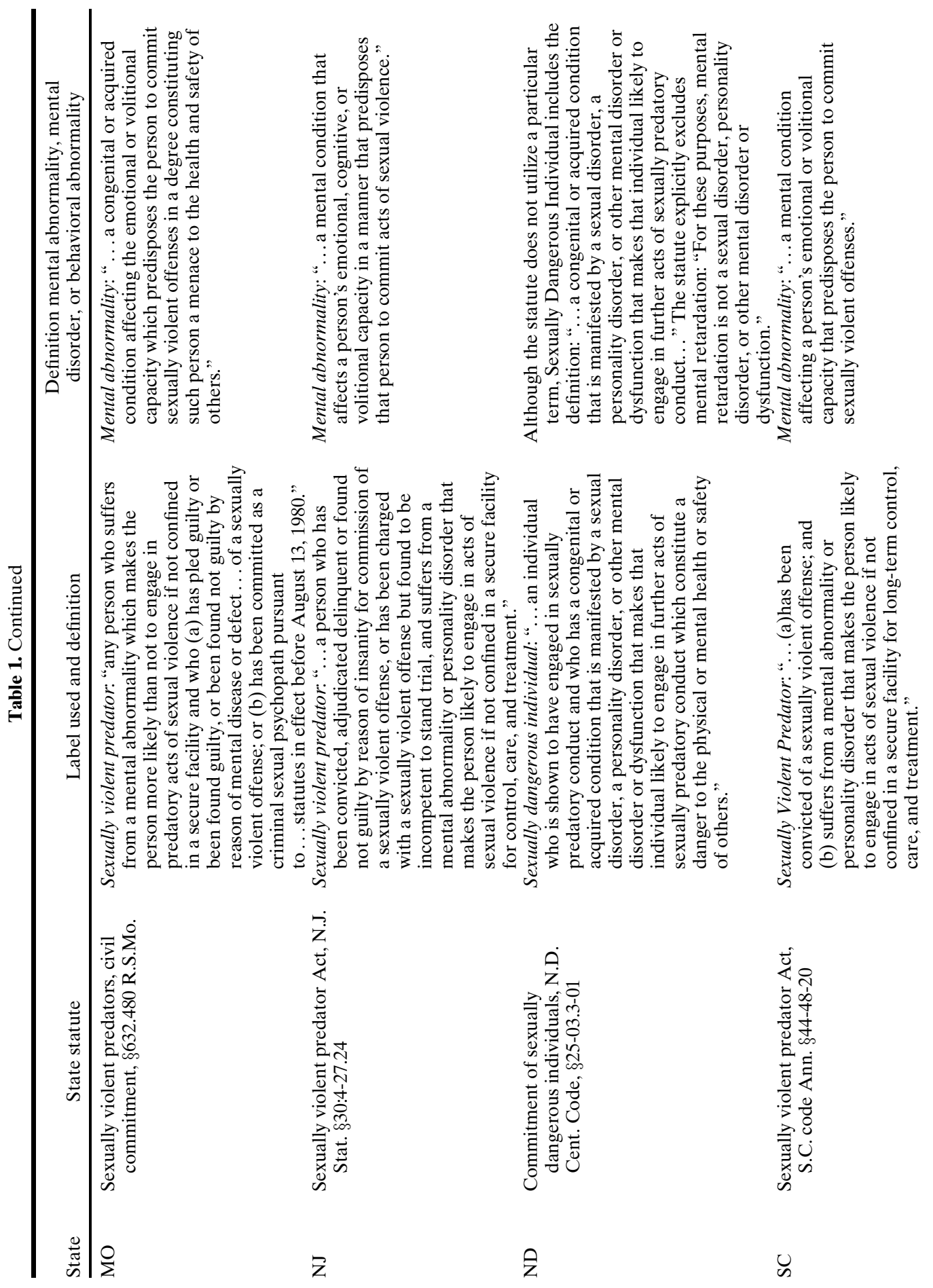



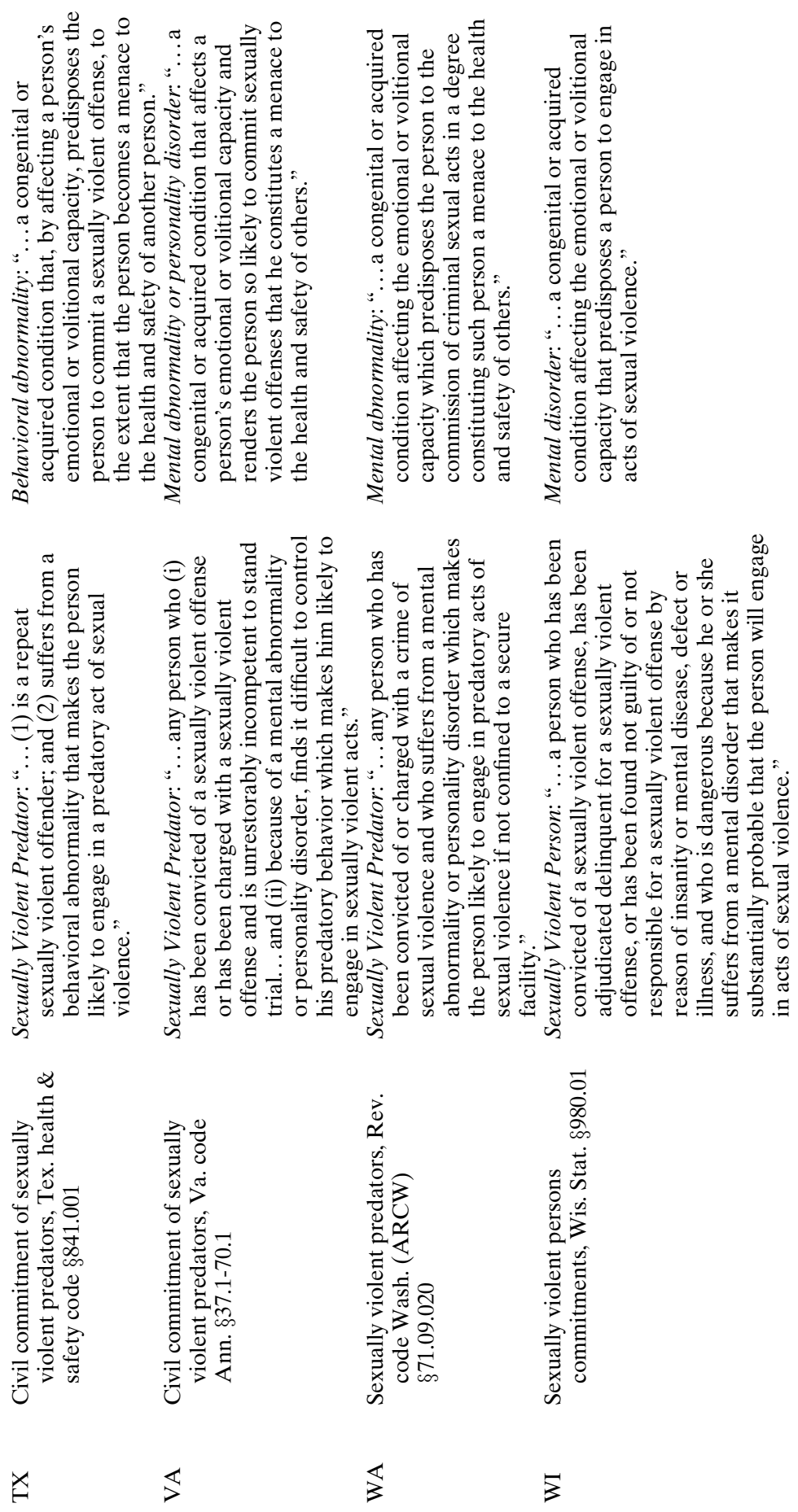
(2) an assessment of risk for certain types of sexual offending" (p. 24). Throughout the book, Doren makes specific recommendations for a multidimensional and ethically sound evaluation. He reviews procedural issues critical to these evaluations (i.e., record review, informed consent, content of the interview with the offender, collateral interviews), diagnostic considerations with different sex offender populations, issues relevant to risk assessment (i.e., methodologies, available instruments, recidivism base rates), and report writing and expert testimony.

In an effort to expand upon the available statutory and professional guidelines, the following sections examine the empirical research for elements common to SVP evaluations: (i) mental abnormality, (ii) volitional capacity, and (iii) likelihood of future sexual violence. Although number of previous sexual offenses necessary to trigger the process is also a common element, this element is statutorily determined and is unlikely to be a consideration for mental health professionals performing such evaluations. In reviewing the literature for each statutory component, we will attempt to present information regarding what areas of a sexual predator assessment have an empirical foundation and what areas have little or no empirical support. Finally, we will discuss appropriate steps the evaluator can take in light of this support (or lack thereof) and what research directions are important in this area of forensic assessment.

\section{EMPIRICAL EVIDENCE FOR EVALUATIONS}

\section{Assessment of Mental Abnormality}

Relevant civil commitment statutes require that the offender being considered for commitment have a mental abnormality. The term mental abnormality has been vaguely defined and is a legal term, not necessarily a diagnosed disorder listed in the Diagnostic and Statistical Manual-Fourth Edition-Text Revision (DSM-IV-TR, American Psychiatric Association, 2000). In other words, the form of abnormality that predisposes the offender to further sexual offenses may be a "diagnosis" such as rape-prone. Although the vagueness of state statutes allows "diagnoses" of symptoms (not included in the DSM) that may be important to risk, there are no formal ways of assessing the reliability or validity of such.

The Association for the Treatment of Sexual Abusers (ATSA; 1997) argues that the process of determining mental/behavioral abnormality within a SVP evaluation should be no different than determining whether someone is mentally disordered under more typical civil commitment procedures. Thus, ATSA recommends there first be a determination of whether the offender has a psychiatric disorder, generally a disorder defined in the DSM-IV-TR (American Psychiatric Association, 2000), followed by establishing an association or link between the disorder, volitional capacity, and a scientific measure of risk. This section will focus on the determination of psychiatric disorder for these evaluations.

Becker, Stinson, Tromp, and Messer (2003) reported the characteristics of a group of sexual offenders petitioned for civil commitment under Arizona's SVP law. The results indicated that within their sample of 120 men, approximately three 
psychiatric disorders (as determined by the DSM) were diagnosed per offender. The authors report the most common disorder was pedophilia (63\%), with frequent occurrences of paraphilia not otherwise specified (56\%). Specific paraphilias such as sexual sadism, exhibitionism, and voyeurism were also quite common (36.5\%). Several other types of DSM disorders, such as personality and substance abuse disorders, were also found in their sample. Data from petitions filed in Texas indicate that pedophilia and antisocial personality disorder have been the most common behavioral abnormalities forming the basis for commitment (Texas Department of Criminal Justice Programs and Services Division, 2002).

Although there were no mental disorders defined outside of the DSM in the Becker or Texas reports, the reliability and validity of several disorders commonly diagnosed among SVP evaluation offenders remain dubious. After the sexual disorders were revised for the DSM-IV (American Psychiatric Association, 1994) and for the DSM-IV-TR (American Psychiatric Association, 2000) little research has examined their reliability and validity. One of the difficulties with reliability and validity research is that there are few, if any, standardized assessment procedures for the diagnosis of sexual disorders. For example, many of the other Axis I disorders can be assessed through structured and semistructured interviews and psychological assessments. These results, combined with clinical interviews allow for the assessment of reliability and validity of diagnoses. To date there is not a structured or semistructured interview for the Paraphilias, nor is there a solid psychological assessment measure that has been successful at aiding in the diagnosis of these disorders. In fact, no instrument, or group of instruments, has yielded a clearly defined set of characteristics, traits, or personality patterns for any group of sex offenders. It appears that most clinicians may rely upon clinical interviews, arrest reports (if applicable and available), possibly phallometric testing (addressed below), and/or develop a tool for assessment. Raymond, Coleman, Ohlerking, Christenson, and Miner (1999) pointed out this diagnostic problem in their study of comorbidity in pedophilic offenders. In an attempt to remedy the lack of structured measures to assess the paraphilias, the authors developed their own semistructured interview for paraphilic diagnoses (and offer it to other researchers for use).

The only successful (albeit semisuccessful) assessment procedure for certain paraphilias has been phallometric testing. Years of research have demonstrated the ability of erectile measurement to differentiate sexually deviant preferences from nondeviant preferences (Hall, Shondrick, \& Hirschman, 1993; Harris \& Rice, 1996; Harris, Rice, Quinsey, Chaplin, \& Earls, 1992; Lalumiere \& Harris, 1998; Lalumiere \& Quinsey, 1994). Penile plethysmograph measurement is typically done in one of two ways: circumference and volumetric procedures. The second is considered the most accurate measurement, especially when attempting to measure low levels of response (Kuban, Barbaree, \& Blanchard, 1999). However, the majority of historical research using phallometric testing utilizes the circumference measurement. Besides different measurement strategies across studies, varied stimulus presentation makes generalization a significant problem. The plethysmograph measurement is stimulated (or not) by pictures, scenes, clips, and/or audio dialogue. The audio dialogue and/or visual stimuli vary on violence level and age of actors. 
Besides generalizability issues, research has demonstrated that the plethysmograph can be successfully faked (e.g., Marshall \& Fernandez, 2000; Wilson, 1998). Studies have indicated that both offenders and nonoffenders can significantly inhibit their arousal (Henson \& Rubin, 1971; Murphy \& Barbaree, 1994). Individuals are seemingly able to use cognitive strategies to distract themselves during perceived inappropriate stimuli and/or to excite themselves during perceived appropriate stimuli. Because faking takes place at the cognitive level, detection is very difficult. Although more sensitive plethysmograph methods (volume changes) are available, the ability to fake the phallometric assessment will remain a problem.

All of that being said plethysmography does show promise in specific areas. Hanson and Bussiere (1998) completed a meta-analysis of 61 sexual offender recidivism studies and found that a pedophile index derived from phallometric evaluation was the most powerful predictor of sexual re-offense $(r=.32)$. However, a similarly constructed rape index did not significantly predict recidivism. These findings are consistent with other studies that have yielded much more positive results in the utility of phallometric assessment with pedophilic versus rape sexual offenders (see Marshall \& Fernandez, 2000 for a review).

Both recent reviews of the literature and years of individual research results indicate that the plethysmograph effectively discriminates between pedophilic and nonpedophilic sexual interest/preference. Of greatest concern is the sensitivity of the procedure. Sensitivity indicates the percentage of sexually deviant individuals identified as such, whereas specificity indicates the percentage of sexually nondeviant individuals being classified as nondeviant. The majority of phallometric studies have indicated very high specificity, but much lower sensitivity (Blanchard, Klassen, Dickey, Kuban, \& Blak, 2001; Freund, Watson, \& Dickey, 1991). The good news is that a nondeviant individual is less likely to be wrongly classified (especially in pedophilic offenders); however, since false negatives are more common, an offender who does not demonstrate deviant results on the plethysmograph may not be accurately diagnosed. This is problematic when considering the time and cost that a phallometric assessment incurs and that other assessment methods are few and far between. Additionally, when examining the studies on sexual offenders and the plethysmograph, it is important to note how each study defines their offender groups. Since diagnosis of the paraphilias is not based on standardized interviews or other assessments, definitions of sexual offenders, especially pedophiles, differ between studies.

O'Donohue, Regev, and Hagstrom (2000) point out that pedophilia, as well as most of the sexual disorders in the DSM-IV (American Psychiatric Association, 1994) were ignored during the version's field trials even though the diagnostic criteria changed from the DSM-III-R to the DSM-IV. Additionally, the paraphilia criteria changed again from the DSM-IV to the DSM-IV-TR. The editors of the DSM-IV-TR removed the necessity of the individual's distress and social/occupational impairment from the sexual urges in criterion B of the paraphilia disorders (Hilliard \& Spitzer, 2002). Thus, similar to the criterion B of paraphilias in the DSM-III-R, individuals can now meet the criteria of a paraphilia if they act on their sexual urges (against a nonconsenting person) whether or not it causes distress or impairment in their overall functioning. Since these DSM 
version changes there seems to be little empirical information about the reliability and validity of pedophilia or other sexual disorders. Additionally, O'Donohue et al. (2000) note "the DSM-IV diagnosis of pedophilia is virtually ignored by both practitioners and researchers" (p. 96). The authors state that the criteria are vague, include constructs that are not verifiable, and have no method of being measured.

What makes the pedophilia diagnosis even more dubious for SVP evaluators is that although many sexual offenders who are petitioned for civil commitment have committed more than one sexual offense against a child over a 6-month period, the question remains whether this diagnosis represents underlying pathology or is simply a description of past behavior. High-risk sexual offenders are ordinarily assessed for civil commitment during the last months of their incarceration after several months or years of imprisonment. Thus, unless they admit to having recurrent (more than once within a 6 month time frame) sexual urges or fantasies regarding children, or demonstrate sexual attraction for this age group on the plethysmograph, Pedophilia is diagnosed via past behavior (historical diagnosis). If the offender has not had the opportunity to offend, does not admit to current aberrant sexual urges or fantasies during the evaluation, or does not appear sexually deviant on the plethysmograph (if used), is the diagnosis still appropriate 5, 10, or even 20 years later? Is it possible that through time and/or treatment that pedophilia can be "in remission?" Currently, the diagnostic criteria do not allow for such.

In addition to the stated issues with the diagnosis of pedophilia, there are also reported problems with other frequently diagnosed sexual disorders. For example, Marshall, Kennedy, Yates, and Serran (2002) conducted a study to examine the interrater reliability of the sexual sadism diagnosis. The authors sent 12 vignettes (half with diagnosis of sexual sadism) to a sample of forensic psychiatrists. Fifteen out of 24 forensic psychiatrists completed the diagnostic task. Results indicated an overall rate of agreement of $75 \%$. However, when chance was taken into account, a kappa of .14 was provided, indicating a much lower rate of agreement. The authors concluded that there is little evidence to encourage confidence in the diagnostic criteria of sexual sadism.

Not only are the sexual disorder diagnoses fraught with reliability and validity questions, currently there is not a diagnosis to capture most offenders who have committed rape. In the Becker et al. (2003) study, the authors reported approximately $28 \%$ of their sample of sexual offenders had committed rape, forcible rape, or attempted rape. Numerous evaluators have utilized the diagnosis "paraphilia not otherwise specified" to apply to rapists. However, the definition of this appellation is so amorphous that no research has ever been conducted to establish its validity (in fact the word rape is not even mentioned in the Paraphilia NOS diagnostic description). How such a diagnosis would differentiate a class of rapists who suffer from a mental abnormality is very unclear. Although previous studies have indicated that the diagnosis of sexual sadism accounts for only $2-5 \%$ of offenders who commit rape (Quinsey, Chaplin, \& Varney, 1981), there remains a large portion of rapists who do not meet the criteria for any paraphilia.

Unlike the commonly diagnosed disorders (within SVP evaluations) discussed above, there is a wealth of literature that demonstrates the use of tools to aid 
the SVP evaluator in diagnosing personality disorders. Commonly used structured (or semistructured) interviews include the Structured Interview for DSM-IV Personality Disorders (SIDP-IV; Pfohl, Blum, \& Zimmerman, 1995), the Structured Clinical Interview for DSM-IV Personality Disorders (SCID-II; First, Gibbon, Spitzer, Williams, \& Benjamin, 1997), and the Personality Disorder Examination (PDE; Loranger, 1988). For a review of commonly used diagnostic interviews for personality disorders see Rogers (2001). Additionally, there are psychological instruments that provide information for Axis II disorders. For example the Millon Clinical Multiaxial Inventory-III (MCMI-III; Millon, Davis, \& Millon, 1997) is a selfreport personality measure that assesses personality disorder traits, although not without debate (see Rogers, Salekin, \& Sewell, 1999; Wiener, 2000 for overviews of the forensic application of the MCMI-III).

\section{Assessment of Volitional Capacity}

In Kansas v. Hendricks (1997), the Supreme Court noted-not less than 17 times-the necessity of linking some mental abnormality or personality disorder with an offender's lack of ability to control dangerous sexual behavior. Four years later, the same Court reiterated that some lack of control must be demonstrated in order to distinguish the SVP from the typical criminal recidivist (Kansas v. Crane, 2002). Subsequent state cases have emphasized establishing the connection of mental disorder to behavioral control difficulties (In re Thorell, 2003) and demonstrating that the behavior is a product of the disorder or abnormality and not simply a matter of volitional choice (In re Leon G., 2002). The Minnesota Court of Appeals specified expert testimony as a critical element in this determination, saying there must be "... a judicial finding of 'lack of control' based on expert testimony tying that 'lack of control' to a properly diagnosed mental abnormality or personality disorder before civil commitment may occur" (In re Martinelli, 2002, p. 886). Attorneys wanting expert testimony concerning personality disorders in regard to civil commitment are generally seeking a witness who will speak to some factor that would impair control (Schopp, Scalora, \& Pearce, 1999).

Experts have attempted in various ways to provide evidence regarding the issue of control. Testimony given to the court in Kansas $v$. Hendricks (1997) indicated that the diagnosis of pedophilia qualified as the kind of mental disorder called for in the statute. In Kansas v. Crane (2002), an expert opined that together, two conditions (exhibitionism and antisocial personality disorder) met the requirements specified in the statute.

In the professional literature, Doren (2002) suggests that simply the diagnosis of pedophilia makes a predisposition self-evident. Under this premise the strength of the sexual desire is so overwhelming that the individual is unable to resist.

The person may very well have learned from prior (direct and vicarious) experiences, and incorporated that learning into his decision-making process as indicated in the limited options he considers. If the person repetitively limits his perceived options based on a continuing type of sexual desire, then this process represents impairment in his decision making. Paraphilias often signal this type of impairment (Doren, 2002, p. 17). 
Hoberman describes the lack of self-control as a common sense dimension:

A sexual offender with a propensity for a particular deviant sexual arousal who does not control that arousal and who initiates sexual behavior when he perceives the opportunity of a potential victim demonstrates a difficulty, or in extreme cases an inability, to control his behavior. (Hoberman, 1999, pp. 9-29).

He goes on to say that further inferences regarding ability to control can be drawn from the records of the offender's behavior and from results of personality measures (i.e., Minnesota Multiphasic Personality Inventory-2; Butcher, Dahlstrom, Graham, Tellegen, \& Kaemmer, 1989). On the other hand, Becker and Murphy (1998), while stressing the importance of the diagnosis of some paraphilia for SVP civil commitment, admit that there is currently no data that would equate these diagnoses with volitional impairment.

The legal community has long complained that there is no consensus within the mental health profession regarding the relationship between control and mental disorder (McAllister, 1998). Evidence for this view includes the competing briefs submitted to the court in Kansas v. Hendricks. Legal scholars have noted that patterns of healthy human behavior tend to be consistent with personality traits, yet these are not labeled "beyond volitional control" (Janus, 1998, p. 319). Serious concern has been raised regarding the overall lack of empirical support for the notion that persons diagnosed with paraphilias or personality disorders are unable to control their behavior or that these disorders result in any unique difficulty in controlling behavior (Morse, 1998; Schopp \& Sturgis, 1995; Winick, 1998).

In the early 1980s, the American Psychiatric Association joined with the American Bar Association in recommending that the volitional prong of the ALI standard for insanity be eliminated. This recommendation was based on the contention that volition was virtually impossible for a mental health professional to measure (La Fond, 2000). It was becoming increasingly clear that many of the mental abnormalities were constructs, not supported by the same scientific structures as physical diseases. The preface to the DSM-IV-TR makes clear that no particular diagnosis implies any degree of control over the behaviors that might be associated with that disorder (American Psychiatric Association, 2000). Whereas many of the medical disorders represent the conjunction of pathology and etiology with signs and symptoms, many psychopathologies - particularly personality disordersare signs and symptoms alone (Lilienfeld, Waldman, \& Israel, 1994). Yet the simple inclusion of personality disorders and paraphilias under the broader umbrella of mental disorders - the same umbrella that shades schizophrenia, dementia, and major affective disorders - may imply there is some definable entity, distinct from the behaviors and manifestations themselves, causing the symptoms. To date, however, our science has identified no such entity.

Perhaps the most promising area of research likely to establish scientific evidence of diminished behavioral control is psychophysiological. Prentky and Burgess (2000) discuss psychosis, organicity, senility, and mental retardation as disinhibiting factors that may "... contribute to the relaxation of controls and the expression of a preexisting tendency to engage in a particular behavior" (p. 34). Hare and others have been assembling data regarding neuropsychological correlates of psychopathy (Kiehl, Hare, McDonald, \& Brink, 1999; Kiehl, Smith, Hare, \& Liddle, 2000; Raine 
et al., 2003). Various orbitofrontal abnormalities have been reported to be associated with poor impulse controls, aberrant sexual behavior, and personality disorders (Bechara, Damasio, \& Damasio, 2000; Blair \& Cipolotti, 2000; Saver \& Damasio, 1991). At least one case study has been published linking pedophilic symptoms with a right orbitofrontal tumor (Burns \& Swerdlow, 2003). Yet, what evidence that exists remains correlational. There is no empirical proof that an individual diagnosed with a personality disorder or paraphilia actually has a neuropsychological abnormality, or, if present, the degree to which that abnormality may impair behavioral control. If it is, in fact, the neuropsychological abnormality that is decreasing the individual's ability to control behavior, why not utilize that abnormality directly and not rely on a personality disorder that is only a correlate of the root problem? However, in reality, neuropsychological diagnoses are not commonly used as the basis for sex offender commitments. Additionally, the target behaviors in the sex offender population are often well organized and goal directed, not the very impulsive acts commonly associated with neurological abnormalities.

In 1987, Rogers suggested possible criteria for assessing volitional capacity. He proposed examining loss of capacity to make choices, incapacity for delay, disregard for apprehension, foreseeability and avoidability, and whether the deficit was a result of mental illness. However, a generally accepted operational definition has failed to emerge. Not only is there no method developed by which to assess behavioral control, there is no clear definition of what is being measured. Any standard would appear to be more normative than scientific. To scientifically evaluate an individual's difficulty in controlling certain behaviors, one would need some way to calibrate what constitutes more or less difficulty.

In 2002, the U.S. Supreme Court provided some limited guidance on the role of behavioral control in determining whether an individual qualified for civil commitment.

With respect to the civil commitment of dangerous sexual offenders under the statute, the Federal Constitution required the state to prove that such offenders had serious difficulty in controlling their behavior. Such required proof-when viewed in light of such features of the case as the nature of the psychiatric diagnosis and the severity of the mental abnormality itself-had to be sufficient to distinguish the dangerous sexual offender whose serious mental illness, abnormality, or disorder subjected the offender to civil commitment from the dangerous but typical recidivist convicted in an ordinary criminal case (Kansas v. Crane, 2002, p. 607).

The question to be addressed would seem to be why a particular person has greater difficulty directing his or her sexual behavior than the average person or than the average sex offender. Even if such degrees of control could be measured, it would be another matter to connect the deficit directly to one of the paraphilias or to a personality disorder. This becomes particularly problematic given that the most commonly applied diagnoses are primarily based upon behavioral descriptors. Personality disorders and paraphilias differ in significant ways from many other diagnostic categories. Unlike neuropsychological disorders, no physiological deficits have been demonstrated and linked to the behaviors. Unlike many of the psychotic disorders, no brain scans have demonstrated abnormalities. Unlike many of the disorders described in the DSM, no specific treatments have been demonstrated to be 
highly effective. Unlike many other disorders, the criteria for pedophilia and antisocial personality disorder can be met completely from behavior described in records. It would seem tautological, and certainly not scientific to argue that the offender has pedophilia because he/she commits sexual acts against children and he/she commits sexual acts against children due to that pedophilic condition. Translating this premise into the control paradigm: the offender lacks the ability to control his/her behavior because the person fails to control that behavior.

\section{Assessment of Sexual Recidivism}

Although most state statutes focus on the relationship of the above variables to determine whether a sexual offender is a danger to recidivate sexually, most SVP evaluators include some formal assessment of risk that utilizes measures. This is one area where forensic assessment has made enormous progress, going from Monahan's (1981) report on the overrated clinical prediction of violence to more recent findings where studies consistently report the relationship between certain variables/instruments and recidivism (e.g., Harris, Rice, \& Quinsey, 1993; Kroner \& Loza, 2001; Loza \& Green, 2003; Salekin, Rogers, \& Sewell, 1996). Multiple studies have demonstrated the relationship between specific variables and sexual reoffense (e.g., Barbaree, Seto, Langton, \& Peacock, 2001; Hanson \& Bussiere; 1998; Hanson $\&$ Thornton, 2000). Thus, mental health professionals are able to offer the court consistent evidence that certain factors (and scores on actuarial instruments) are associated with an increased likelihood of sexual recidivism.

The number of actuarial instruments available to readers has "burgeoned" in recent years (Barbaree et al., 2001, p. 491). Instruments such as the Violence Risk Appraisal Guide (VRAG; Quinsey, Harris, Rice, \& Cormier, 1998), the Sex Offender Risk Appraisal Guide (SORAG; Quinsey et al., 1998), the Minnesota Sex Offender Screening Tool-Revised (MnSOST-R; Epperson, Kaul, Huot, Goldman, \& Alexander, 2003), and the Static-99 (Hanson \& Thornton, 2000) have all received considerable empirical attention. Although a review of literature associated with each instrument is beyond the scope of the present paper, comprehensive reviews of each instrument and theoretical commentary regarding the application of actuarial risk assessment instruments in the context of sex offender civil commitment proceedings are available (Barbaree et al., 2001; Campbell, 2000; Conroy, 2002; Doren, 2002; Hanson, 1998; Hanson \& Thornton, 2000; Hart, 2003; Hoberman, 1999; Quinsey et al., 1998; Rice \& Harris, 1997, 2002; Sreenivasan, Kirkish, Garrick, Weinberger, \& Phenix, 2000).

Although recent advances in the risk assessment literature are commended, limitations of the extant body of research should be acknowledged. First, the classifying (in research and in treatment) of sexual offenders as one group may be problematic when attempting to understand empirical results. Second, research on recidivism has focused almost exclusively on static rather than dynamic (or changing) variables. Thus, if a sexual offender successfully completes treatment while incarcerated, it is not known whether his/her static risk level should be modified. Third, there is conflicting research examining the relationship between psychopathy and sexual re-offending. 


\section{Sexual Offenders as One Group}

One of the consistent problems with sexual offender research, whether it examines the utility of methods to predict recidivism or assesses the effects of treatment, is the lumping of sexual offenders into one group. Research has indicated significant differences between types of sexual offenders, including rates of recidivism (e.g., Doren \& Epperson, 2001; Furby, Weinrott, \& Blackshaw, 1989; Hanson \& Bussiere, 1998; Rice \& Harris, 1997). For example, incest offenders recidivate at lower rates than extrafamilial child molesters who target victims of the opposite sex (Quinsey et al., 1998) who, in turn, recidivate at lower rates than extrafamilial child molesters who target victims of the same sex (Hanson, Steffy, \& Guthiere, 1993). Thus, lumping sexual offenders into one group to examine the utility of risk assessment measures may significantly affect the findings of studies that have done so. Additionally, several groups of sexual offenders have been almost entirely ignored within the literature. These include noncontact sexual offenders such as exhibitionists, voyeurists, and frotteurists. Becker et al. (2003) reported that $32 \%$ of their sample was diagnosed with one or more of these disorders.

In a recent study examining the differences in predictive validity of actuarial risk assessments in relation to offender type, Bartosh, Garby, Lewis, and Gray (2003) investigated the effectiveness of four risk instruments utilizing subgroups of offenders. The sample included 73 rapists, 59 extrafamilial child molesters, 37 incest child molesters, and 17 noncontact sexual offenders. Results indicated that the effectiveness of each measure was related to offender type. The authors conclude, "offender type should play an important role in determining the course of risk assessment" (Bartosh et al., 2003, p. 436). Although these results contradict previous reports of no sexual offender type differences in actuarial prediction (e.g., Hanson \& Thornton, 2000; Sjostedt \& Langstrom, 2001) and are limited because of small sample sizes, further research is warranted examining possible group differences and risk prediction.

\section{Importance of Dynamic Risk Variables}

Several recent studies have indicated the importance of the relationship between dynamic variables and risk for recidivism (e.g., Beech, Friendship, Erikson, \& Hanson, 2002; Dempster \& Hart, 2002; Hanson \& Bussiere, 1998; Hanson \& Harris, 2000; Thornton, 2002). For example, Hanson \& Harris (2000) present data that demonstrate dynamic variables such as criminal attitudes, social influence, and hostility are related to sexual recidivism. Although researchers are identifying important dynamic variables that should be taken into account when evaluating risk, only a small number of such measures are currently being developed and these remain in their infancy. Instruments such as the Sex Offender Need Assessment Rating (SONAR; Hanson \& Harris, 2001) have shown promise, but more research is needed. Additionally, there are no standards of how to take dynamic variables into account and/or combine them with more established static variables when determining risk. In other words, if and how these variables do change and whether they decrease risk is unknown at this time. For example, if a sexual offender modifies criminal attitudes within the treatment setting, rids himself of antisocial influence, 
and reduces anger, will that be enough to significantly decrease his level of risk? In order for the SVP evaluator to take dynamic variables into account, research needs to illuminate the relationship between these variables and risk.

\section{Use of Psychopathy in Risk Determination}

Although psychopathy has not generally been used as a diagnostic category to provide evidence for a mental illness for insanity or incompetence to stand trial evaluations, it is being utilized to define mental abnormality in SVP evaluations. In Texas the statute even mandates psychopathy assessment. The court's understanding of psychopathy has serious implications for the offender. If an offender is reported to have psychopathy, not only is he/she considered untreatable (Coid, 1998; Gunn, 1998), but also the criminal justice system associates his/her psychopathy with violence and recidivism (Shipley \& Arrigo, 2001). In addition to diagnostic confusion between antisocial personality disorder and psychopathy (e.g., Shipley \& Arrigo, 2001), research has been mixed regarding the relationship between psychopathy and sexual recidivism (Barbaree et al., 2001; Brown \& Forth, 1997; Dorr, 1998; Hanson \& Harris, 2000; Porter et al., 2000; Quinsey et al., 1998).

Evaluators need to be cautious both when psychopathy is and is not evident. Although there is solid evidence that psychopathy is a good predictor of general and violent recidivism, the findings regarding the relationship between psychopathy and sexual re-offending are less consistent (Barbaree et al., 2001; Firestone et al., 2000; Porter et al., 2000; Quinsey et al., 1998). Strongest support for psychopathy as predictive of sexual recidivism has been found when it interacts with deviant sexual interests (e.g., Rice \& Harris, 1997). Additionally, the absence of psychopathic traits is not indicative of a low risk to sexually re-offend in and of itself. There are many offenders with pedophilia, especially those who offend outside the family, who do not have high levels of psychopathy, but remain a high risk to recidivate sexually (Firestone et al., 2000). As highlighted by Becker et al. (2003), the majority (63\%) of offenders petitioned for civil commitment in their sample were diagnosed with pedophilia. Many of the sexual offenders diagnosed with pedophilia do not have psychopathic personalities and typically have fewer psychopathic traits than other types of sexual offenders (e.g., rapists and mixed offenders; Porter et al., 2000).

\section{SUMMARY}

The above review highlights the empirical strengths and limitations of SVP evaluations. In the assessment of mental abnormality, although evaluators commonly diagnose offenders with disorders such as pedophilia and paraphilia not otherwise specified, little empirical information is available regarding the reliability and validity of these disorders. In addition, the diagnosis of sexual disorders and sexual crimes such as rape are made difficult by problematic diagnostic criteria, the (often) historical basis of the diagnosis, and a lack of a diagnostic category to capture offenders who commit rape. Although the assessment of specific paraphilias through phallometric testing is promising, especially among pedophilic 
offenders, the plethysmograph can be faked and problems with its generalizability and sensitivity exist.

There is presently no consensus in the field regarding the relationship between behavioral control and mental abnormality. In addition to the lack of agreed upon methodology to assess "inability to control," at present there is no consistently utilized definition of just what is being assessed. Although psychophysiological research being conducted represents a promising area of research, evidence linking personality disorders or paraphilias to neuropsychological abnormalities is, at present, correlational. There is no empirically established link between a diagnosis of personality disorder or paraphilia and a neuropsychological condition; nor is there evidence to suggest the extent to which a physiological abnormality impairs behavioral control among individuals diagnosed with personality disorders or paraphilias.

Although consistent evidence regarding the relationship between certain variables and scores on actuarial instruments and the likelihood of sexual recidivism is rapidly accumulating, problems with sexual recidivism research complicate the assessment of risk in the context of SVP evaluations. Classification of sex offenders into homogeneous groups potentially obscures empirical findings among studies examining the utility of risk assessment measures. In addition, research on methods to measure dynamic variable risk is only beginning and; there are no widely accepted standards to account for changes in such variables in the context of an SVP risk assessment. Empirical support regarding the relationship between psychopathy and sexual recidivism has been inconsistent and evaluators must use caution regarding level of risk both when psychopathy is and is not present. Presented below are additional considerations for evaluators faced with the task of conducting a scientifically sound assessment in this legal arena followed by research directions that would increase the empirical foundation of SVP evaluations.

\section{Strategies for Evaluators}

Perhaps the most basic principle for SVP evaluators is to avoid providing opinions on issues beyond the competence of the discipline. For example, regardless of attorney requests, opinions on issues such as whether the examinee meets statutory criteria as a repeat sex offender should be left to the legal system.

Terms such as "mental abnormality" or "behavioral abnormality" are legal inventions and not clinically recognized diagnoses. Legal definitions are sufficiently vague that an exact translation into diagnostic categories lacks any reasonable degree of clinical certainty. Nonetheless, mental health professionals can assist the trier of fact by providing clinical diagnoses from the DSM-IV-TR, provided their meaning is carefully explained. Diagnoses such as schizophrenia, dementia, depression, or mental retardation-common in many clinical populations-are relatively rare in sex offenders pending commitment proceedings. By far the majority of sex offenders are committed on the basis of a paraphilia or a personality disorder. While many offenders may meet the criteria specified in the DSM-IV-TR, it is essential that evaluators explain what these diagnoses actually mean. For the most part they are behavioral descriptors or, stated another way, signs and symptoms absent 
demonstrated pathology and etiology. For example, a person who is at least 16 years of age and has molested a child (or children) more than once over a 6-month period has met the diagnostic criteria for Pedophilia. Some legal experts have suggested that such a category is so behaviorally explicit that anyone could arrive at the diagnosis with an adequate record and a command of the English language (Schopp et al., 1999). Thus, to truly inform the court, it becomes necessary to explain that some diagnoses are not disease entities that invade the systems of helpless, unsuspecting organisms.

Degree of behavioral control is perhaps the element of most SVP standards that is farthest from the realm of competence of mental health professionals. Volitional control is not scientifically demonstrable, yet easily implied by the linguistically careless. Phrases such as "leads to ...," "results in ...," "manifests as ...," or "predisposes to...," suggest that some identified phenomenon is in some way responsible for the individual's failure to control sexual behaviors. However, to suggest the existence of something beyond signs and symptoms, manifested as behavior, is simply to reify a construct. There is no scientific data identifying something that is causing loss of control, let alone a loss measurable in degrees of difficulty. While an evaluator can report that an individual repeatedly fails to exercise control, even in the face of severe negative consequences, it is best left to the trier of fact to determine whether this is a case of "cannot" or "will not."

Prediction of human behavior in any context is difficult and, at best, imperfect. Yet the last two decades has seen an explosion in the data available on the prediction of violence risk and, in particular, the risk of sexual offender recidivism. While that data clearly remains inadequate if one expects to provide a simple "yes" or "no" answer regarding risk, the mental health professional has a considerable body of evidence available that can assist the trier of fact in a way that goes well beyond chance and/or clinical judgment alone. Actuarial data can be helpful if presented in the context of its limitations. A number of factors have correlated repeatedly with risk for recidivism, while others have shown no relationship or a negative relationship. Making the most current information available to legal decision-makers provides a valuable service.

A number of newly developed actuarial instruments can be very useful to the evaluator provided they are used selectively and with reasonable caution. As with any psychometric instrument, they should provide an important piece of data or lead the evaluator to a hypothesis. However, scores should not be interpreted as the final answer to the question of risk. Such reliance would assume that all possible variables impacting risk are covered in the instrument's formula and that these risk factors should be weighted in exactly the same way for all individuals. Even those most enthusiastic about this approach (Quinsey et al., 1998) have stopped short of this conclusion. The very newness of these tools must temper our embracing them unabashedly. Research bases are still developing. As was recently the case with the MnSOST-R, despite very positive initial research, contrary data may subsequently appear (Seto \& Barbaree, 1999). This may serve to effectively discredit an evaluation that relies too heavily upon an actuarial instrument. Additionally, since each actuarial instrument assesses different variables and was developed with different populations (although there is 
certainly overlap), using more than one of these measures may be appropriate. The more corroborative data the instruments produce, the higher the probable accuracy of prediction. Further, the more similar the evaluated offender is to the actuarial instrument's development sample, the better it is predictive of future behavior.

Whether mental health professionals should address the "ultimate issue" in any forensic case has long been a matter of debate. However, given the legal criteria specified for SVP evaluations and the state of the science in the field, if there were ever a strong argument not to opine on the ultimate issue, it is here. Evaluators can lend greatest service to the trier of fact by providing a well-explained clinical diagnosis and a scientifically based risk assessment.

\section{Research Directions}

In order to improve the empirical basis of SVP evaluations, further research is warranted within each of the statutory elements described above. The following section outlines research directions that would provide empirical support for components of SVP evaluations that are, as yet, not well supported.

Diagnostic categories have very important implications for sexual offenders, especially those petitioned for civil commitment. A diagnosis of sexual sadism or psychopathy, for example, may influence several individuals and systems that make decisions for the offender. Therefore, evidence of high diagnostic reliability and validity are warranted, particularly with the diagnoses most common in SVP evaluations. Due to the change in sexual disorder criteria via DSM-IV and DSM-IV-TR renewed research examining reliability and validity of these disorders would aid the SVP evaluator. Additionally, the development of measures to aid in accurate and reliable diagnosis would undoubtedly improve accuracy. For example, the development of structured or semistructured interviews for the sexual disorders (like we have for most diagnostic categories) would allow for increased reliability in sexual disorder diagnosis.

In addition to the development of diagnostic interviews for the sexual disorders, the further development of and research on tools to assess these disorders without depending upon the candor of the offender would aid accurate assessment. Future research that demonstrates methods for increasing the sensitivity of the plethysmograph would continue the promise of this measure's ability to assist in accurate assessment and diagnosis of sexual deviance and disorder. Research on additional tools that do not rely on offender frankness or require a lengthy and expensive administration apparatus is also warranted. For example, Seto and Lalumière (2001) reported initial results of the Screening Scale for Pedophilic Interests (SSPI) that could possibly be utilized as a screen for sexual deviance for those evaluations that cannot/do not use the plethysmograph. Seto and Lalumière found that this index predicted plethysmograph verified pedophilic interests above chance levels $(\mathrm{ROC}=$ .70). Another area of sexual deviance assessment that holds promise is attitudinal research. Previous study has reported the relationship between criminal and prooffending attitudes and recidivism (e.g., Hanson, 2003). Future research is warranted to further understand this association and how best to assess it. Criminal 
or pro-offending attitudes may be effectively examined through a form of implicit attitude paradigm assessment.

Future research is also warranted to examine the diagnostic difficulty with offenders who commit rape. The debate of including a specific paraphilic rape diagnosis in the DSM may need to be fully resurrected. Additionally, if rape and other sexual disorders already listed in the DSM are, in fact, mental disorders, and not simply behavioral descriptors, underlying etiology and pathology need to be clearly identified.

In addition to further reliability and validity information on sexual and personality disorders, research is needed that examines the relationship among diagnosis, risk, and recidivism. Although there is evidence indicating that certain types of offenders are more likely to recidivate (i.e., rapists, mixed offenders; Porter et al., 2000), there is little knowledge of base rates for specific sexual disorder types (i.e., pedophiles, exhibitionists, sexual sadists), or dually diagnosed offenders. It may be that certain types of sexual disorders, or combinations of disorders, increase the likelihood of sexual recidivism. For example, individuals who have diagnoses of paranoid schizophrenia and substance abuse are significantly more likely to act violently (Walsh, Buchanan, \& Fahy, 2002). It may be that pedophiles or sexual sadists who abuse substances are also significantly more likely to recidivate than individuals with a pedophilic disorder alone. Additionally, further research not only should clarify the relationship between offender type and risk differences, but also on typologies within these offender groups. The focus thus far has been almost exclusively on specific offense behavior, with the majority of attention given to type of victim. Is this to imply that men who rape adult women are a homogenous group? This would seem to assume that these individuals have similar personality structures, similar motives, and similar treatment response, because they prey upon similar victims. Clearly no evidence currently available would support this assumption.

The area of volitional control is the element of sexual predator evaluations that would appear to have the least empirical support or scientific evidence. We have no data that identifies something that causes lack of control or degrees of control. The most promising area of research for this element seems to be physiological or neuropsychological in nature. Currently there is growing evidence indicating that certain offenders, particularly psychopaths and violent offenders may have different physiological/neurological underpinnings that increase the likelihood of violent behavior (Bechara, et al., 2000; Blair \& Cipolotti, 2000; Burns \& Swerdlow, 2003; Kiehl et al., 2000). Research in this area may continue to provide evidence that brain function (or brain abnormality) affects volition. However, it is important to note that actual testing must establish the presence of neurological or neuropsychological deficits rather than simply assuming offenders who are psychopathic or incarcerated have brain abnormalities because correlational evidence has been found.

Although most state sexual violent predator statutes do not mandate specific actuarial risk assessments, many evaluators utilize instruments that provide evidence of risk level. The field of forensic assessment has been very successful in the last decade in identifying variables that are related to sexual recidivism. However, the understanding of dynamic risk variables remains in its infancy. There are 
several dynamic variables that appear to be significantly related to sexual recidivism; however, research provides no evidence of whether these measured variables indeed do change, or what kind of change is needed to reduce an offender's level of static risk. As clinicians, we believe that variables such as criminal or pro-sexual offending attitudes, hostility levels, and impulse control can change. However, we have little data to support resulting changes in sexual behavior. Additionally, if in fact these variables do change through time, imprisonment, and/or treatment, researchers need to examine to what extent they need to change to reduce the likelihood of sexual recidivism.

To date there have been few instruments developed to assess dynamic risk. The SONAR (Hanson \& Harris, 2001) was developed with released offenders being supervised in the community and assesses stable and acute risk variables through interview. Since the SONAR was developed with community supervised prior offenders there are several variables that relate only to this specific circumstance. For example, the SONAR assesses cooperation with supervision. Unless the SONAR is slightly modified and validated for use with incarcerated offenders, this tool would be limited in its use for SVP commitments, unless the evaluator is in Texas where civilly committed offenders do live in the community supervised or after conditional release to the community in other state programs. One known study has modified the SONAR for use in an incarcerated sexual offender sample (Guy, Torres, Miller, \& Kwartner, 2004). In this initial examination of the slightly modified version, results demonstrated good psychometric properties and its ability to detect change in the stable dynamic risk factors over approximately 1 year of sexual offender treatment. However, before the SONAR can be used in these circumstances, or any other, much further research is needed to replicate the few studies that have utilized this instrument.

To date, psychopathy is one of the best predictors of future recidivism, above all violent recidivism. However, research findings have been mixed in reporting the relationship between psychopathy and sexual re-offending. Further studies are warranted to increase knowledge of this relationship particularly because the diagnosis of psychopathy has been found to be a significant predictor of civil commitment (Levenson, 2003).

\section{REFERENCES}

American Psychiatric Association. (1994). Diagnostic and statistical manual of mental disorders - fourth version. Washington, DC: Author.

American Psychiatric Association. (2000). Diagnostic and statistical manual of mental disorders-text revision. Washington, DC: Author.

Association for the Treatment of Sex Abusers. (1997). Ethical standards and principles for the management of sexual abusers. Beaverton, OR: Author.

Barbaree, H. E., Seto, M. C., Langton, C. M., \& Peacock, E. J. (2001). Evaluating the predictive accuracy of six risk assessment instruments for adult sex offenders. Criminal Justice and Behavior, 28(4), 490521.

Bartosh, D. L., Garby, T., Lewis, D., \& Gray, S. (2003). Differences in the predictive validity of actuarial risk assessments in relation to sex offender type. International Journal of Offender Therapy and Comparative Criminology, 47(4), 422-438.

Bechara, A., Damasio, H., \& Damasio, A. R. (2000). Emotion, decision-making and the orbitofrontal cortex. Cerebral Cortex, 10, 295-307. 
Becker, J. V., \& Murphy, W. D. (1998). What we know and do not know about assessing and treating sex offenders. Psychology, Public Policy, and Law, 4, 116-137.

Becker, J. V., Stinson, J., Tromp, S., \& Messer, G. (2003). Characteristics of individuals petitioned for civil commitment. International Journal of Offender Therapy and Comparative Criminology, 47, 185-195.

Beech, A., Friendship, C., Erikson, M., \& Hanson, R. K. (2002). The relationship between static and dynamic risk factors and reconviction in a sample of U.K. child abusers. Sexual Abuse: A Journal of Research and Treatment, 14(2), 155-167.

Blair, R. J. R., \& Cipolotti, L. (2000). Impaired social response reversal: A case of acquired sociopathy. Brain, 123, 1122-1141.

Blanchard, R., Klassen, P., Dickey, R., Kuban, M. E., \& Blak, T. (2001). Sensitivity and specificity of the phallometric test for pedophilia in nonadmitting sex offenders. Psychological Assessment, 13(1), $118-126$.

Brown, S. L., \& Forth, A. E. (1997). Psychopathy and sexual assault: Static risk factors, emotional precursors, and rapist subtypes. Journal of Consulting and Clinical Psychology, 65, 848-857.

Burns, J. M., \& Swerdlow, R. H. (2003). Right orbitofrontal tumor with pedophilia symptom and constructional apaxia sign. Archives of Neurology, 60, 437-440.

Butcher, J. N., Dahlstrom, W. G., Graham, J. R., Tellegen, A., \& Kaemmer, B. (1989). MMPI2(Minnesota Multiphasic Personality Inventory-2): Manual for administration and scoring. Minneapolis: University of Minnesota Press.

California Welfare and Institutions Code $\$ 6600$ (2003).

Campbell, T. W. (2000). Sexual predator evaluations and phrenology: Considering issues of evidentiary reliability. Behavioral Sciences and the Law, 18, 111-130.

Coid, J. (1998). The management of dangerous psychopaths in prison. In T. Millon \& E. Simonsen (Eds.), Psychopathy: Antisocial, criminal, and violent behavior (pp. 431-457). New York, NY: Guilford Press.

Commitment of Sexually Violent Predators Act, Kan. Stat. Ann. §59-29a02 (2002).

Conroy, M. A. (2002). Assessment of sexual offenders. In B. Van Dorsten (Ed.), Forensic psychology: From classroom to courtroom (pp. 219-246). New York: Kluwer/Plenum.

Dempster, R. J., \& Hart, S. D. (2002). The relative utility of fixed and variable risk factors in discriminating sexual recidivists and nonrecidivists. Sexual Abuse: A Journal of Research and Treatment, 14(2), 121-138.

Doren, D. M. (2002). Evaluating sex offenders: A manual for civil commitment and beyond. Thousand Oaks, CA: Sage.

Doren, D. M., \& Epperson, D. L. (2001). Great analysis, but problematic assumptions: A critique of Janus and Meehl (1997). Sexual Abuse: A Journal of Research and Treatment, 13(1), 45-51.

Dorr, D. (1998). Psychopathy in the pedophile. In T. Millon, E. Simonsen, M. Birket-Smith, \& R. Davis (Eds.), Psychopathy: Antisocial, criminal, and violent behavior. New York, NY: The Guilford Press.

Epperson, D. L., Kaul, J., Huot, S., Goldman, R., \& Alexander, W. (2003). Minnesota sex offender screening tool-revised (MnSOST-R): Development, validation, and recommended risk level cut scores. $\mathrm{Re}-$ trieved from Iowa State University, Department of Psychology. http://www.psychology.iastate.edu/ faculty/epperson/TechUpdatePaper12-03.pdf.

Firestone, P., Bradfore, J. M., McCoy, M., Greenberg, D. M., Curry, S., \& Larose, M. R. (2000). Prediction of recidivism in extrafamilial child molesters based on court-related assessments. Sexual Abuse: A Journal of Research and Treatment, 12(3), 203-221.

First, M. B., Gibbon, M., Spitzer, R. L., Williams, J. B. W., \& Benjamin, L. (1997). The Structured Clinical Interview for DSM-IV Axis II Personality Disorders (SCID-II). Washington, DC: American Psychiatric Press.

Fitch, W. L. (1998). Sex offender commitment in the United States. The Journal of Forensic Psychiatry, 9(2), 237-240.

Freund, K., Watson, R. J., \& Dickey, R. (1991). Sex offenses against female children perpetrated by men who are not pedophiles. Journal of Sex Research, 28, 409-423.

Furby, L., Weinrott, M. R., \& Blackshaw, L. (1989). Sex offender recidivism: A review. Psychological Bulletin, 105(1), 3-30.

Gunn, J. (1998). Psychopathy: An elusive concept with moral overtones. In T. Millon \& E. Simonsen (Eds.), Psychopathy: Antisocial, criminal, and violent behavior (pp. 32-39). New York, NY: Guilford Press.

Guy, L., Torres, A., Miller, H. A., \& Kwartner, P. (2004, March). Using the SONAR to evaluate change in sexual offender risk level over treatment. Paper presented at the Annual National Conference of the American Psychology and Law Society, Scottsdale, Arizona.

Hall, G. C. N., Shondrick, D. D., \& Hirschman, R. (1993). The role of sexual arousal in sexually aggressive behavior: A meta-analysis. Journal of Consulting and Clinical Psychology, 61, 1091-1095. 
Hanson, R. K. (1998). What do we know about sex offender risk assessment? Psychology, Public Policy, and Law, 4(1/2), 50-72.

Hanson, R. K. (2003). Who is dangerous and when are they safe? Risk assessment with sexual offenders. In B. Winick \& J. LaFond (Eds.), Protecting society from sexually dangerous offenders: Law, justice, and therapy. Washington, DC: American Psychological Association.

Hanson, R. K., \& Bussiere, M. T. (1998). Predicting relapse: A meta-analysis of sexual offender recidivism studies. Journal of Consulting and Clinical Psychology, 66, 348-362.

Hanson, R. K., \& Harris, G. T. (2000). Where should we intervene? Dynamic predictors of sex offense recidivism. Criminal Justice and Behavior, 27, 6-35.

Hanson, R. K., \& Harris, G. T. (2001). A structured approach to evaluating change among sexual offenders. Sexual Abuse: A Journal of Research and Treatment, 13(2), 105-122.

Hanson, R. K., Steffy, R. A., \& Guthiere, R. (1993). Long term recidivism of child molesters. Journal of Consulting and Clinical Psychology, 61(4), 646-652.

Hanson, R. K., \& Thornton, D. (2000). Improving risk assessments for sex offenders: A comparison of three actuarial scales. Law and Human Behavior, 24, 119-136.

Harris, G. T., \& Rice, M. E. (1996). The science of phallometric testing of male sexual interest. Current Directions Psychological Science, 5, 156-160.

Harris, G. T., Rice, M. E., \& Quinsey, V. L. (1993). Violent recidivism of mentally disordered offenders: The development of a statistical prediction instrument. Criminal Justice and Behavior, 20, 315335.

Harris, G. T., Rice, M. E., Quinsey, V. L., Chaplin, T. C., \& Earls, C. (1992). Maximizing the discriminate validity of phallometric assessment data. Psychological Assessment, 4, 502-511.

Hart, S. D. (2003). Actuarial risk assessment: Commentary on Berlin et al. Sexual Abuse: A Journal of Research and Treatment, 15(4), 383-388.

Henson, D. E., \& Rubin, H. B. (1971). Voluntary control of eroticism. Journal of Applied Behavior Analysis, 4, 38-44.

Hilliard, R. B., \& Spitzer, R. L. (2002). Change in criterion for paraphilias in DSM-IV-TR. American Journal of Psychiatry, 159(7), 1249.

Hoberman, H. M. (1999). Expert witness report and testimony in sexual predator civil commitment proceedings. In A. Schlank (Ed.), The sexual predator: Law, policy, evalution, and treatment (pp. 11:111:57). Kingston, NJ: Civic Research Institute.

In re the Detention of Thorell, 72 P. 3d 708 (S.Ct. WA 2003).

In re the Matter of Leon G., 59 P. 3d 779 (AZ S.Ct. 2002).

In re the Matter of Alexander Mark Martinelli, 649 N.W. 2d 886 (MN App. 2002).

Janus, E. S. (1998). Hendricks and the moral terrain of police power civil commitments. Psychology, Public Policy and Law, 4, 297-322.

Kansas v. Crane, 534 U.S. 407 (2002).

Kansas v. Hendricks, 521 U.S. 346 (1997).

Kiehl, K. A., Hare, R. D., McDonald, J., \& Brink, J. (1999). Semantic and affective processing in psychopaths: An event-related potential (ERP) study. Psychophysiology, 36, 765-774.

Kiehl, K. A., Smith, A. M., Hare, R. D., \& Liddle, P. F. (2000). An event-related potential investigation of response inhibition in schizophrenia and psychopathy. Biological Psychiatry, 48, 210-221.

Kroner, D., \& Loza, W. (2001). Evidence for the efficacy of self-reporting in predicting nonviolent and violent criminal recidivism. Journal of Interpersonal Violence, 16(2), 168-177.

Kuban, M. E., Barbaree, H. E., \& Blanchard, R. (1999). A comparison of volume and circumference phallometry: Response magnitude and method agreement. Archives of Sexual Behavior, 28, 345359.

La Fond, J. Q. (2000). The future of involuntary civil commitment in the USA after Kansas v. Hendricks. Behavioral Sciences and the Law, 18, 153-167.

Lalumiere, M. L., \& Harris, G. T. (1998). Common questions regarding the use of phallometric testing with sexual offenders. Sexual Abuse: A Journal of Research and Treatment, 10, 227-237.

Lalumiere, M. L., \& Quinsey, V. L. (1994). The discriminability of rapists from non-sex offenders using phallometric measures: A meta-analysis. Criminal Justice and Behavior, 21, 150-175.

Lanyon, R. I. (2001). Psychological assessment procedures in sex offending. Professional Psychology: Research and Practice, 32, 253-260.

Levenson, J. S. (2003). Factors predicting recommendations for civil commitment of sexually violent predators under Florida's Jimmy Ryce Act (Doctoral Dissertation, Florida International University, 2003). Dissertation Abstracts International, 64(3-A), 1079.

Lilienfeld, S. O., Waldman, I. D., \& Israel, A. C. (1994). A critical examination of the use of the term and concept of comorbidity in psychopathology research. Clinical Psychology: Science and Practice, $1,71-83$. 
Loranger, A. W. (1988). Personality Disorder Examination (PDE) manual. Yonkers, NY: DV Communications.

Loza, W., \& Green, K. (2003). The self-appraisal questionnaire: A self-report measure for predicting recidivism versus clinician-administered measures: A 5-year follow-up study. Journal of Interpersonal Violence, 18(7), 781-797.

Marcotty, J. (2003, June 22). State looks to release sexual psychopaths. The Star Tribune, pp. A1, A20.

Marshall, W. L., \& Fernandez, Y. M. (2000). Phallometric testing with sexual offenders: Limits to its value. Clinical Psychology Review, 20(7), 807-822.

Marshall, W. L., Kennedy, P., Yates, P., \& Serran, G. (2002). Diagnosing sexual sadism in sexual offenders: Reliability across diagnosticians. International Journal of Offender Therapy and Comparative Criminology, 46(6), 668-677.

McAllister, S. R. (1998). Sex offenders and mental illness: A lesson in federalism and the separation of powers. Psychology, Public Policy, and Law, 4, 268-296.

Millon, T., Davis, R., \& Millon, C. (1997). Millon Clinical Multiaxial Inventory-III (2nd ed.). Minneapolis: National Computer Systems.

Monahan, J. (1981). The clinical prediction of violent behavior. Washington, DC: U.S. Government Printing Office.

Morse, S. J. (1998). Fear of danger, flight from culpability. Psychology, Public Policy, and Law, 4, 250267.

Murphy, W. D., \& Barbaree, H. E. (1994). Assessments of sex offenders by measures of erectile response: Psychometric properties and decision making. Brandon, VT: The Safer Society Press.

O'Donohue, W., Regev, L. G., \& Hagstrom, A. (2000). Problems with the DSM-IV diagnosis of pedophilia. Sexual Abuse: A Journal of Research and Treatment, 12, 95-105.

Pfohl, B., Blum, N., \& Zimmerman, M. (1995). The Structured Interview for DSM-IV Personality: SIDP$I V$. Iowa City: University of Iowa.

Porter, S., Fairweather, D., Drugge, J., Herve, H., Birt, A., \& Boer, D. P. (2000). Profiles of psychopathy in incarcerated sexual offenders. Criminal Justice and Behavior, 27(2), 216-233.

Prentky, R. A., \& Burgess, A. W. (2000). Forensic management of sexual offenders. NY: Kluwer Academic/Plenum Publishers.

Quinsey, V. L., Chaplin, T. C., \& Varney, G. (1981). A comparison of rapists' and non-sexoffenders' sexual preferences for mutually consenting sex, rape, and sadistic acts. Behavioral Assessment, 3, 127-135.

Quinsey, V. L., Harris, G. T., Rice, M. E., \& Cormier, C. A. (1998). Violent offenders: Appraising and managing risk. Washington, DC: American Psychological Association.

Raine, A., Lencz, T., Taylor, K., Hellige, J. B., Bihrle, S., Lacasse, L., et al. (2003). Corpus collosum abnormalities in psychopathic antisocial individuals. Archives of General Psychiatry, 60, 11341142.

Raymond, N., Coleman, E., Ohlerking, F., Christenson, G., \& Miner, M. (1999). Psychiatric comorbidity in pedophilic sex offenders. American Journal of Psychiatry, 156(5), 786-788.

Reid, W. (2002). Sexual predator evaluations and commitments. Law and Psychiatry, 8, 1-5.

Rice, M. E., \& Harris, G. T. (1997). Cross-validation and extension of the Violence Risk Appraisal Guide for child molesters and rapists. Law and Human Behavior, 21(2), 231-241.

Rice, M. E., \& Harris, G. T. (2002). Men who molest their sexually immature daughters: Is a special explanation required? Journal of Abnormal Psychology, 111, 329-339.

Rogers, R. (2001). Handbook of Diagnostic and Structured Interviewing. New York, NY: The Guildford Press.

Rogers, R. (1987). APA's position on the insanity defense: Empiricism versus emotionalism. American Psychologist, 42, 840-848.

Rogers, R., Salekin, R. T., \& Sewell, K. W. (1999). Validation of the Millon Multiaxial Inventory for Axis II disorders: Does it meet the Daubert standard? Law and Human Behavior, 23, 425-443.

Salekin, R. T., Rogers, R., \& Sewell, K. W. (1996). A review and meta-analysis of the psychopathy checklist and psychopathy checklist-revised: Predictive validity of dangerousness. Clinical Psychology: Science and Practice, 3(3), 203-215.

Saver, J. L., \& Damasio, A. R. (1991). Preserved access and processing of social knowledge in a patient with acquired sociopathy due to ventromedial frontal damage. Neuropsychologia, 29, 12411249.

Schopp, R. F., Scalora, M. J., \& Pearce, M. (1999). Expert testimony and professional judgment: Psychological expertise and commitment as a sexual predator after Hendricks. Psychology, Public Policy, and Law, 5, 120-174.

Schopp, R. F., \& Sturgis, B. J. (1995). Sexual predators and legal mental illness for civil commitment. Behavioral Sciences and the Law, 13, 437-458. 
Seto, M. C., \& Barbaree, H. E. (1999). Psychopathy, treatment behavior, and sex offender recidivism. Journal of Interpersonal Violence, 14, 1235-1248.

Seto, M. C., \& Lalumière, M. L. (2000). Psychopathy and sexual aggression. In C. B. Gacono (Ed.), The clinical and forensic assessment of psychopathy: A practitioner's guide (pp. 333-350). Mahwah, NJ: Erlbaum.

Seto, M. C., \& Lalumière, M. L. (2001). A brief screening scale to identify pedophilic interests among child molesters. Sexual Abuse: A Journal of Research and Treatment, 13(1), 15-25.

Shipley, S., \& Arrigo, B. (2001). The confusion over psychopathy (II): Implications for forensic (correctional) practice. International Journal of Offender Therapy and Comparative Criminology, 45(4), 407-420.

Sjostedt, G., \& Langstrom, N. (2001). Actuarial assessment of sex offender recidivism risk: A corssvalidation of the RRASOR and the Static-99 in Sweden. Law and Human Behaviort, 25, 629-645.

Sreenivasan, S., Kirkish, P., Garrick, T., Weinberger, L. E., \& Phenix, A. (2000). Actuarial risk assessment models: A review of critical issues related to violence and sex-offender recidivism assessments. The Journal of the American Academy of Psychiatry and the Law, 28, 428-448.

Texas Department of Criminal Justice Programs and Services Division. (2002, September). Civil commitment. Austin, Texas: Author.

Texas Health \& Safety Code $\S 841.000$ (2000).

Thornton, D. (2002). Constructing and testing a framework for dynamic risk assessment. Sexual Abuse: A Journal of Research and Treatmentt, 14(2), 139-153.

Virginia Code Annotated $\S 37.1-70.5$ (2004).

Walsh, E., Buchanan, A., \& Fahy, T. (2002). Violence and schizophrenia: Examining the evidence. British Journal of Psychiatryt, 180(6), 490-495.

Wiener, R. (Ed.). (2000). Point and counterpoint: Forensic use of the Millon Inventories [Adversarial Forum]. Law and Human Behavior, 24(4), 485-506.

Wilson, R. J. (1998). Psychophysiological signs of faking in the phallometric test. Sexual Abuse: A Journal of Research and Treatmentr, 10, 113-126.

Winick, B. J. (1998). Sex offender law in the 1990s: A therapeutic jurisprudence analysis. Psychology, Public Policy, and Law, 4, 505-570. 